\title{
ENTRE ENXADAS E MÁQUINAS: ENSINO AGRÍCOLA, TRABALHO, TRADIÇÃO E MODERNIZAÇÃO NA AGRICULTURA ${ }^{1}$
}

\author{
Daniela Pereira Versieux \\ Centro Federal de Educação Tecnológica de Minas Gerais (CEFET-MG) \\ Fundação de Ensino de Contagem (FUNEC) \\ Irlen Antônio Gonçalves \\ Centro Federal de Educação Tecnológica de Minas Gerais (CEFET-MG)
}

\section{RESUMO}

O presente artigo tem como objeto de estudo o ensino agrícola pensado, planejado e executado pelo Estado de Minas Gerais nas duas primeiras décadas republicanas. Constituem nossos objetivos explicitar a relação existente entre o ensino agrícola, a agricultura e a instalação em Minas Gerais de uma modernidade capitalista; e compreender como o ensino agrícola fez parte do processo de modernização pelo qual passava a sociedade mineira do início da República, inserindo-se nos esforços que as elites condutoras do Estado empreenderam para subjugar a "rotina" ou a tradição que imperava na lida agrária, com vistas à modernização do campo. Utilizamos como categorias de análise: escolarização, modernidade, modernização e tradição; além do ensino agrícola como categoria histórica. A partir da leitura de algumas fontes primárias e de um profícuo diálogo com a literatura pudemos inferir que o ensino agrícola contribuiu para a modernização agrícola ao impor um determinado modo de fazer agricultura, substituindo práticas, métodos, conhecimentos e instrumentos tradicionais pelos modernos métodos agrícolas, retirando dos trabalhadores a possibilidade de uma sobrevivência autônoma e imprimindo ao processo modernizador um caráter de expropriação.

Palavras-chave: história do ensino agrícola, modernização da agricultura, tradição na agricultura, escolarização.

\section{BETWEEN HOE AND MACHINES: AGRICULTURAL SCHOOLING, AGRICULTURAL WORK, TRADITION AND MODERNIZATION IN AGRICULTURE}

\section{ABSTRACT}

This paper aims to study that the agricultural education thought, planned and executed by the state of Minas Gerais in the first two decades of the Republic. This objectives are explain the relationship between agricultural education, agriculture in Minas Gerais and the installation of a capitalist modernity, and understand how the agricultural education was part of the modernization process by which the Minas Gerais society spent the early Republic, by inserting efforts in conducting the elites of the state undertook to subdue the "routine" or the tradition that prevailed in the land deals, to modernize the field. Used as analytical categories: education, modernity, modernization and tradition, besides the agricultural education as a historical category. From reading some primary sources and a fruitful dialogue with the literature we could infer that agricultural education has contributed to agricultural modernization by imposing a particular way of farming, replacing practices, methods, knowledge and traditional instruments with modern agricultural methods, workers removing the possibility of an autonomous survival and printing a modern character in the process of expropriation.

Keywords: agricultural schooling history, agricultural modernization, agricultural tradition, schooling 
Sem esse meio [o ensino agrícola], é força confessar, o lavrador primitivo ficará diante dessas máquinas [agrícolas] fazendo o mesmo papel que o boi a olhar para palácio

Viriato Diniz Mascarenhas².

\section{Introdução}

A epígrafe que abre este artigo remete à representação - coletiva e individual - que parte das elites de Minas Gerais possuía do trabalhador rural: como bois que olhavam palácios, pouco se diferenciavam dos animais usados na lavoura, apenas parte de um processo produtivo. Deveriam ser adestrados, educados e instruídos para que eles próprios fizessem a substituição desejada pelas elites: máquinas, no lugar de homens. E esta meta foi perseguida durante toda a primeira república: substituir por máquinas agrícolas os braços nacionais que não queriam se submeter ao trabalho racional, metódico, sistematizado e disciplinado na lavoura.

Os primeiros anos após a instauração da República foram marcados, em Minas Gerais e no restante do Brasil, pela transição do trabalho escravo para o trabalho livre. Minas - um Estado essencialmente agrário - encontrava-se nos estágios iniciais de seu processo de modernização. Nesse momento, havia uma carência de mão de obra para a agricultura. Uma das soluções encontradas pelas elites condutoras mineiras para esse problema constituiu-se na tentativa de substituição parcial dos trabalhadores por máquinas agrícolas e a instrução de alguns desses trabalhadores para o manejo das máquinas que se queria introduzir. É nesse contexto que as elites assumem o ensino agrícola como estratégia modernizadora do campo.

Assim, constituem-se objetivos do presente artigo explicitar a relação existente entre o ensino agrícola, a agricultura e a instalação em Minas Gerais de uma modernidade capitalista; e compreender como o ensino agrícola fez parte do processo de modernização pelo qual passava a sociedade mineira do início da República, inserindo-se nos esforços que as elites condutoras do Estado empreenderam para substituir a "rotina" ou a tradição que imperava na agricultura por novos e modernos métodos e instrumentos de trabalho.

Para atingir tais metas restringimos o período pesquisado às duas primeiras décadas da República. E utilizamos como fontes primárias a legislação do Estado de Minas Gerais; artigos do jornal Minas Gerais; alguns relatórios produzidos pela secretaria de Agricultura do Estado de Minas Gerais; bem como alguns textos dos anais do Congresso Legislativo de Minas Gerais.

Adotamos como ponto de partida o imaginário, expresso por alguns republicanos do final do século XIX e início do XX, de que Minas Gerais era um Estado essencialmente agrícola e que passava por uma crise econômica. Tal crise, na perspectiva das elites mineiras, só poderia ser resolvida enfrentando de forma articulada três questões que perpassavam a vida social mineira: o povoamento do solo, a capacitação técnica do trabalhador do campo e a mudança de hábitos e costumes de lida com a terra, qual seja o abandono da "rotina" em favor dos novos e modernos métodos e instrumentos de trabalho agrícola e pecuário. Diante desse diagnóstico, já presente nas primeiras discussões do Congresso Legislativo Mineiro, ainda no século XIX, o ensino agrícola foi assumido como uma das estratégias de solucionar politicamente a crise econômica do Estado.

A solução da crise econômica do Estado passava, necessariamente, na perspectiva das elites contemporâneas, pela instrução técnica e profissional da população mineira e 
pela modernização da agricultura. Falar em modernização era, e ainda é, falar em modernidade. Para Jean Baudrillard

[...] a modernidade não é nem um conceito sociológico, nem um conceito político, nem propriamente um conceito histórico. Ela é um modo de civilização característico, que se opõe ao modo da tradição, isto é, a todas as outras culturas anteriores ou tradicionais: face à diversidade geográfica e simbólica destas, a modernidade se impõe como una, homogênea, que se irradia mundialmente a partir do Ocidente. No entanto, ela encerra uma noção confusa, que conota globalmente toda uma evolução histórica e uma mudança de mentalidade. (BAUDRILLARD, 1977, p. 139).

A modernidade, por não ser um conceito, não tem leis, existindo somente "traços de modernidade" (BAUDRILLARD, 1977, p. 139), sendo possível, contudo, indicar algumas de suas características. A modernidade pode ser vista como "prática social e modo de vida articulado sobre a mudança, a inovação, mas também sobre a inquietude, a mobilização contínua, a subjetividade movediça, a tensão, a crise, e como representação ideal ou mitológica" (BAUDRILLARD, 1977, p. 140). A modernidade é também a "era da produtividade: intensificação do trabalho humano e da dominação humana sobre a natureza, um e outro reduzidos ao status de forças produtivas e aos esquemas de eficácia e de rendimento máximos" (BAUDRILLARD, 1977, p. 140). Esse é, segundo o autor, o denominador comum entre as nações modernas.

Num sentido próximo, mas com uma maior clareza, em função da caracterização contraditória que faz da modernidade, Marshall Berman chama a atenção para o conjunto de experiências "de tempo, espaço, de se si mesmo e dos outros, das possibilidades e perigos da vida", de que homens e mulheres compartilham. É esse conjunto contraditório que caracteriza o que ele chamou de modernidade. A contradição expressa, por um lado, uma promessa de "ventura, poder alegria, crescimento, autotransformação e transformação das coisas" e, por outro, apresenta-se destruidora de tudo que tem e produziu a humanidade. Assim, viver a contradição é fazer parte do moderno e, nesse universo, tomando a expressão de Marx, "tudo o que é sólido desmancha no ar" (BERMAN, 1999, p. $15)$.

Entendendo assim a modernidade, a modernização está articulada a ela enquanto uma ideologia da mesma, e enquanto um de seus traços peculiares, como concebido por Baudrillard e como "processos sociais que dão vida" ao que Berman chamou de turbilhão "que se mantem num estado de vir-a-ser"1.

Nesse texto, o nosso interesse é ressaltar a modernização da agricultura como um processo contínuo de transformações que se processam num tempo histórico específico, numa dada realidade social e política que se queria identificar-se como moderna. Na esteira de um vir a ser, a modernização da agricultura será apreendida como uma das consequências de uma modernidade requerida pela política pública mineira, por meio da mecanização dos processos de produção agrícola e da racionalização dos saberes escolares, via o processo de escolarização dos saberes da prática tacitamente constitutivo da tradição do trabalhar a terra pelos campos das Minas Gerais.

\section{Modernização, trabalho e ensino agrícola}

\footnotetext{
${ }^{1}$ Os processos sociais que dão vida ao turbilhão, referenciado por Berman (1999), diz respeito aos vários acontecimentos que fizeram parte de um tempo denominado de moderno: descobertas das ciências, industrialização, formas de poder corporativo e luta de classe, surgimento dos Estados nacionais, expansão do mercado capitalista, dentre outros.
} 
Minas Gerais, entre 1889 e 1937, era uma sociedade em seus estágios iniciais de modernização (WIRTH, 1982). Aqui, assim como no Brasil, os processos de modernização foram impulsionados com a abolição da escravidão e a proclamação da República, em fins do século XIX. Segundo Otávio Dulci, "a abolição do sistema escravista [...] havia removido um grande obstáculo à modernização do país, ensejando a constituição de um efetivo mercado de trabalho" (DULCI, 2005, p. 109). À época, as elites econômica, política e intelectual mineiras faziam um diagnóstico de que, após os tempos áureos da mineração, a província de Minas Gerais, depois o Estado, teve sua economia estagnada durante todo o século XIX e início do XX, com sua população dispersa geograficamente e voltada para atividades de subsistência simples, com exceção do limitado surto cafeeiro do oitocentos e de alguns períodos mais favoráveis dos tempos primeiros da República. A leitura dos anais do Congresso Legislativo Mineiro, desse período, revelou que este pensamento circulava pelas classes conservadoras ${ }^{3}$ do Estado.

De acordo com Douglas Cole Libby (1988) este diagnóstico foi, até certo ponto, repetido pela historiografia. De fato, Celso Furtado entendeu que não foram criadas formas permanentes de atividades econômicas nas regiões mineiras, que incluíam não apenas o Estado de Minas, mas também Goiás e Cuiabá, no Mato Grosso,

- à exceção de alguma agricultura de subsistência -". Dessa forma, "era natural que, com o declínio da produção de ouro, viesse uma rápida e geral decadência. [...] a decadência se processava por uma lenta diminuição do capital aplicado no setor mineratório. (FURTADO, 2000, p. 89).

Francisco Iglésias, por seu turno, esforçou-se em demonstrar a "perda de substância da economia mineira" (IGLÉSIAS, 1982, p. 117). Essa expressão foi recorrente nos anos iniciais da República (DULCI, 2005; FARIA, 1992; WIRTH, 1982) e traduzia a percepção das classes conservadoras mineiras do relativo atraso econômico do Estado. Atraso esse percebido em contraste com o passado de riqueza, advinda do ciclo da mineração do ouro, e também com as comparações entre o desenvolvimento mineiro e o de São Paulo, sobretudo. Iglésias afirmou que Minas, durante a primeira República, continuou "em relativa estagnação. Não regride, mas perde substância" (IGLÉSIAS, 1982, p. 139). Logo em seguida, no mesmo texto, asseverou que "na sua caracterização geral, contudo, não se deve falar em retrocesso nem mesmo em estagnação. Houve um crescimento, embora acanhado relativamente a outras áreas. Este, além de pequeno, apresentava-se irregular" (IGLÉSIAS, 1982, p. 141). De qualquer forma, o autor parecia repetir a análise tradicional, mas curvando-se aos dados do crescimento econômico de Minas que ele mesmo apresentou.

Otávio Dulci (2005) e John D. Wirth (1982) confirmam que a economia mineira do período não retrocedeu ou estagnou, a despeito das crises. O diagnóstico das elites era, assim, exagerado, pois a economia mineira apresentou um crescimento, embora em ritmo lento, durante todo o século XIX (DULCI, 2005; WIRTH, 1982). Dessa forma, "o contraste entre esse crescimento moderado e a rápida expansão de outras áreas é que definiria o declínio na posição relativa de Minas em termos nacionais" (DULCI, 2005, p. $115)$.

Douglas Cole Libby concorda que a economia de subsistência foi o grande sustentáculo da economia mineira no período, tanto a destinada ao autoconsumo quanto aquela que visava o mercado interno, dentro e fora da província. Porém, longe de considerá-la como decadente, o autor entende 
[...] que [era] mais correto pensar na evolução da economia mineira ao longo do século passado como um processo de acomodação às adversidades - que provinham, de início, do gradual retraimento das atividades mineradoras e, mais tarde, do lento desmoronamento do regime escravista - em vez de insistir na ideia de uma prolongada estagnação econômica. (LIBBY, 1988, p. 122-123).

Nesse sentido, Libby consegue perceber que foi a agricultura de subsistência a grande absorvedora da mão de obra escrava nas Minas oitocentista, o que teria evitado o colapso do sistema escravista. Esse processo, que ele denominou de "economia de acomodação" (LIBBY, 1988, p. 14), também implicou "o relativo declínio das atividades não-agrícolas. [...] Ao mesmo tempo, o crescimento do setor agrícola pareceu ter desencadeado um complexo processo de proletarização parcial de ampla parcela do elemento livre da população" (LIBBY, 1988, p. 123).

Outro pesquisador que se esforçou em demonstrar o dinamismo da economia mineira do século XIX foi Alcir Lenharo. Este autor identifica na historiografia a secundarização da economia de subsistência, relegando-a a um nível apenas complementar a economia exportadora. Para ele,

[...] quase sempre a economia de subsistência é vista como caracterizada por baixa produtividade e rentabilidade; comumente é caracterizada como uma economia de natureza fechada e tendente à auto-suficiência. As formas de trabalho nela empregadas tendem a diferenciá-la da economia de exportação: nesta utiliza-se extensivamente o trabalho escravo; naquele é mais comum o emprego de formas não escravistas de trabalho. (LENHARO, 1993, p. 26).

Além disso, Lenharo observa

[...] a persistência de um comércio ativo entre as comarcas mineiras e a capitania de Minas com o Rio de Janeiro, como também a manutenção dos níveis de arrecadação dos dízimos. A sociedade mineira resguardara seu caráter essencialmente urbano, e sua estrutura econômica demonstrara capacidade de absorver o impacto da crise. (LENHARO, 1993, p. 28).

A esse processo, de absorção do impacto da crise da mineração, entendemos que Douglas Cole Libby denomina de acomodação, conceito já explicitado. Lenharo, restringindo sua análise ao Sul de Minas na primeira metade do século XIX, especifica melhor a identidade da sua economia de subsistência, caracterizando-a como constituída por "grandes propriedades escravistas voltadas para o abastecimento interno. Criada para o abastecimento das Gerais no século XVIII, a economia regional manteria a mesma natureza por meio do direcionamento do fluxo do seu excedente para o mercado do Rio de Janeiro." (LENHARO, 1993, p. 29). Além disso, essa região de Minas "conheceu um reforço em sua estrutura econômica, já alicerçada na produção mercantil de gêneros de subsistência. Atividades de produção, portanto, que não se relacionavam com tendências de involução ou regressão econômica". (LENHARO, 1993, p. 60).

Nesse contexto, após a abolição, a preocupação com a formação do trabalhador do e para o campo no Brasil ganhou contornos mais nítidos. A partir daí percebeu-se uma desorganização das relações de produção no campo, assentadas até então no regime escravista. Como nos lembra Libby, ao longo do século XIX há proporcionalmente uma 
diminuição do conjunto de escravos nesse período em Minas Gerais. Contudo,

[...] o contingente mancípio mineiro ainda representava um quinto da província em 1872, e os 367.443 cativos mineiros registrados pelo Recenseamento [de 1872] constituíram o maior plantel de escravos de todas as províncias do Império. Tais cifras demonstram a prolongada importância do trabalho escravo para a Província e afastam qualquer hipótese sugerindo que a escravidão teria se tornado residual ao conjunto sócio-econômico mineiro, após a cessação do tráfico negreiro internacional [em 1850]. (LIBBY, 1988, p. 46).

Sérgio Buarque de Holanda (1995), para o Oeste Paulista de meados do Oitocentos, vê na "carência de braços para a lavoura" do café um importante determinante da baixa na produção de alimentos. Para os contemporâneos e gerações seguintes a abolição da escravidão teria aprofundado a crise econômica de Minas Gerais, gerando uma desorganização do mercado de trabalho e consequente falta de braços para a lavoura. Contudo, Celso Furtado sugere que o "problema da falta de braços", previsto com o fim do regime escravocrata, relacionou-se não com a falta de trabalhadores, mas de mão de obra. (FURTADO, 2000).

De acordo com John Wirth, em Minas Gerais, "o impacto da abolição foi grave no início, embora, de modo geral, tenha sido mais um momento político decisivo do que o caos sócio-econômico que os mineiros a princípio temiam." (WIRTH, 1982, p. 79). Houve queda da produção, redução das exportações de café, "os cereais apodreceram nos campos, sem ter quem os colhesse", fazendas faliram, caiu o valor das propriedades. Mas, já em 1891, a produção reorganizou-se. (WIRTH, 1982, p. 79). O autor assinala ainda que as reduções de mão de obra nas regiões cafeicultoras do Estado eram devidas não necessariamente à abolição da escravatura, mas antes aos baixos salários pagos, pois havia trabalhadores que "aceitavam parceria, contratos e sistemas de salário parcial em troca de um pagamento à vista", enquanto uma parcela migrava ou mudava para a agricultura de subsistência (WIRTH, 1982, p. 79): "houve uma escassez de mão de obra [...], mas não uma escassez de mineiros.” (WIRTH, 1982, p. 81).

Em São Paulo também não houve escassez de trabalhadores. Contudo, os braços nacionais eram considerados inaptos para o trabalho sistemático e racional. Lúcio Kowarick (1994), estudando a formação do mercado de mão de obra livre no Brasil, tendo o caso de São Paulo como referência, considera que os trabalhadores nacionais livres e libertos foram marginalizados desde os tempos coloniais e

[...] tendem a não passar pela 'escola do trabalho', sendo frequentemente transformados em itinerantes que vagueiam pelos campos e cidades, vistos pelos senhores como a encarnação de uma corja inútil que prefere a vagabundagem, o vício ou o crime à disciplina do trabalho. O importante nesse processo de rejeição causado pela ordem escravocrata é que qualquer trabalho manual passa a ser considerado como coisa de escravo e, portanto, aviltante e repugnante. (KOWARICK, 1994, p. 43, grifos nossos).

Naquele Estado, a imigração se constituiu como opção principal para suprir a demanda por força de trabalho, além de constituir um necessário mercado de reserva, contornando, dessa forma, o problema da formação do mercado de mão de obra livre. Para Kowarick, "a opção arquitetada pelo grande fazendeiro do café foi a importação em massa da mão de obra, que, empobrecida na Europa, não tinha alternativa senão a de vender, a 
preços aviltantes, sua força de trabalho" (KOWARICK, 1994, p. 65).

A desqualificação dos trabalhadores nacionais deu-se, assim, como uma forma de

[...] retirar-lhes as possibilidades de trabalho recriando as condições materiais de sua marginalização e atribuindo-lhes a pecha de indolentes e indisciplinados.

[...]

$\mathrm{Na}$ realidade, [os nacionais] são refratários ao trabalho organizado, porque, sendo mínimas as suas necessidades, não precisam se alugar para outros de forma contínua. Basta, de quando em vez, uma jornada por semana: de resto, a disponibilidade para nada fazer, além da caça, da pesca, do pequeno plantio e da criação, que permitem a sobrevivência na pobreza e, dessa forma - agora introduzo essa nova dimensão da assim chamada vadiagem -, o desamor ao trabalho e a possibilidade do ócio e do festejo. (KOWARICK, 1994, p. 103-104, grifos nossos).

Em que pese essa análise de Kowarick ser válida apenas para São Paulo, o problema da "vadiação" foi, aqui em Minas, também uma obsessão. Os fazendeiros mineiros "consideravam os trabalhadores volúveis, não confiáveis e desleais, todos querendo viver da terra na ociosidade - em resumo um problema social para as autoridades" (WIRTH, 1982, p. 80, grifo nosso). Ao contrário de São Paulo, as tentativas mineiras de atrair os trabalhadores estrangeiros em geral fracassaram e as classes conservadoras tiveram que investir no aproveitamento do trabalhador nacional. (FARIA, 1992; WIRTH, 1982).

A opção pelo trabalhador nacional deu-se, em Minas, no contexto da assunção, pelas elites política, econômica e intelectual, de um "projeto de desenvolvimento econômico" pautado no "princípio da união na diversidade", que garantiria unidade geográfica e política e evitaria a "perda de substância econômica" por meio da "priorização do incremento à agropecuária diversificada." (FARIA, 1992, p. 13).

Segundo Otávio Dulci, o

[...] desenvolvimento, no terreno socioeconômico, é uma ideia referente à superação intencional de uma situação de atraso relativo. Envolve, portanto, uma clara dimensão política, que se traduz em ações governamentais - mediante graus variáveis de intervenção - e também em articulações de classes e grupos diversos (sobretudo as elites políticas, econômicas e intelectuais) em torno da meta de superação do atraso. Podemos chamar de desenvolvimentismo ao pensamento que focaliza esse processo numa perspectiva de projeto, realçando seu sentido estratégico e seu potencial mobilizador. (DULCI, 2005, p. 114).

Ainda segundo Otávio Dulci, no início do século XX, os termos "desenvolvimento" ou "desenvolvimentismo" não eram usados, mas sim o termo "progresso", mais difuso e menos específico. Para o autor há uma dimensão de "projeto" contida nos discursos das elites mineiras e na intervenção indireta do Estado na economia no início do século XX, o que permitiria tratar do progresso ensejado pelos contemporâneos como desenvolvimento. Este "projeto de desenvolvimento" foi mais bem formulado e explicitado durante o Congresso Agrícola, Comercial e Industrial ocorrido entre 13 e 19 de maio de 1903, em Belo Horizonte, em meio à primeira crise de superprodução do café, que durou de 1897 a 1909 (DULCI, 2005; FARIA, 1992). Reunindo, pela primeira vez, as classes produtoras e a elite intelectual mineiras, foi patrocinado pelo governo de Francisco Sales ${ }^{4}$ e organizado, 
presidido e liderado por João Pinheiro da Silva 5 . Reunião "esmerada", nos dizeres de John D. Wirth, o Congresso Agrícola buscou realizar um rigoroso diagnóstico da então realidade regional e nacional, a partir do qual foi traçado um projeto de desenvolvimento econômico para o Estado (FARIA, 1992; FUNDAÇÃO JP, 1981).

O projeto traçado no Congresso de 1903, e exposto nas teses aprovadas, propôs a construção de alternativa à primazia e consequente dependência econômica em relação à agricultura cafeeira. Nas últimas décadas do século XIX esta lavoura já apresentava um acentuado declínio de produtividade e exportações, principalmente nas antigas zonas produtoras em Minas - da Mata e Sul. Esse declínio de produtividade foi verificado em Minas Gerais, nas regiões citadas, e também no Estado do Rio, devido ao esgotamento dos solos (PIRES, 2004) e pela exiguidade de terras virgens disponíveis para novos cultivos. Essa queda na produtividade foi vinculada, pelas elites, à manutenção das práticas agrícolas rotineiras, ou tradicionais.

Essa alternativa à dependência do café explicava-se também pela necessidade de unificar política e geograficamente o território mineiro, face às disputas que permearam a última década do século, desenvolvendo a vocação do Estado para a agricultura de subsistência, com vistas à conquista do mercado nacional (FARIA, 1992; WIRTH, 1982). De acordo com Maria Auxiliadora Faria,

[...] à concretização desse projeto se interpunham inúmeros obstáculos, dentre eles, o estrutural, da organização das relações de produção no campo. Em Minas, ao moroso processo de passagem para o trabalho livre, somaram-se, desde o século XIX, os fracassos de uma política imigrantista pouco consistente, o intenso movimento de dispersão da população trabalhadora tanto para os sertões do Mato Grosso e Goiás, quanto para as lavouras de São Paulo e do Rio de Janeiro. Nesse quadro, a defesa e o implemento do ensino agrícola, destinado a crianças e adultos, teria emergido, não apenas como forma inovadora de lidar com a agricultura e a pecuária, mas também como mecanismo de controle social dos trabalhadores, garantindo sua presença no campo e assiduidade ao trabalho. Assim concebido, o ensino agrícola integra o projeto de desenvolvimento econômico mineiro da Primeira República como uma de suas principais metas. (FARIA, 1992, p. 13-14, grifos nossos).

Assim, Maria Auxiliadora Faria explicita o vínculo estreito entre economia, agricultura e ensino agrícola. Compreendemos a expressão ensino agrícola como uma categoria histórica, que expressava um caráter profissional e não era necessariamente vinculada a algum nível de escolaridade. Podia ser um ensino primário-elementar, quando associado à instrução elementar (ler e contar); médio ou técnico, formando agrônomos de nível médio, técnicos agrícolas ou mestres de cultura; ou ainda ser ministrado em escolas superiores de agricultura, formando agrônomos de nível superior (VERSIEUX, 2010). Caracterizou também esse ensino a sua vinculação, ao menos desde o início da República até meados do século XX, às pastas de Agricultura (secretarias estaduais, ministério), ficando apartado da educação mais geral. (MENDONÇA, 1998).

O ensino agrícola foi compreendido, durante a Primeira República, como "estratégia utilizada pelo Estado não apenas para a formação profissional dos trabalhadores, mas também para a sua retenção no campo". Nesse período, a despeito das várias tentativas do Estado em implantá-lo, ou seja, de transformar seu discurso em prática, "o insucesso foi, contudo, a marca principal da maioria [delas]." (FARIA, 1992, p. 269). Maria Auxiliadora Faria segmenta a trajetória desse ensino em Minas Gerais na Primeira 
República em três momentos distintos, nos quais "se superpuseram rupturas e permanências." (FARIA, 1992, p. 309). No QUADRO I, a seguir, expusemos essa segmentação elaborada por Faria, que complementamos com algumas informações obtidas a partir da documentação consultada durante a pesquisa empírica empreendida.

Para a autora, o ensino agrícola esteve presente no discurso e na prática dos primeiros republicanos mineiros. Contudo, enquanto fundamento da política econômica, só foi plenamente formulado e implantado a partir do Congresso Agrícola de 1903 e da administração de João Pinheiro da Silva. (FARIA, 1992). Até então "apesar da consciência de que o ensino agrícola poderia ser utilizado como dinamizador do desenvolvimento, as tentativas empreendidas foram frustradas, pois de modo geral, o ensino agrícola não saiu da esfera discursiva." (FARIA, 1992).

QUADRO I

Fases do ensino agrícola, Minas Gerais, 1889-1930

\begin{tabular}{|c|c|c|c|}
\hline & Primeira fase & Segunda fase & Terceira fase \\
\hline Período & $1889-1903$ & $1903-1920$ & $1920-1930$ \\
\hline Tipo de ensino & $\begin{array}{l}\text { Teórico-prático, em todos os níveis } \\
\text { (superior, médio e elementar) }\end{array}$ & Prático e elementar & $\begin{array}{l}\text { Teórico-prático; técnico e } \\
\text { superior }\end{array}$ \\
\hline $\begin{array}{l}\text { Instituições } \\
\text { criadas }\end{array}$ & $\begin{array}{l}\text { Institutos Agronômicos, Institutos } \\
\text { Zootécnicos e Campos de } \\
\text { Demonstração }\end{array}$ & $\begin{array}{l}\text { Fazendas-modelo, fazendas } \\
\text { particulares subvencionadas pelo } \\
\text { Estado, campos de demonstração e } \\
\text { de experiências, institutos primário- } \\
\text { agrícolas, aprendizados agrícolas }\end{array}$ & $\begin{array}{l}\text { Escola Superior de Agricultura e } \\
\text { Veterinária de Minas Gerais } \\
\text { (ESAV), em Viçosa }\end{array}$ \\
\hline Objetivos & \multicolumn{2}{|c|}{$\begin{array}{l}\text { Fixação dos trabalhadores no campo; reorganização do trabalho e } \\
\text { mecanização do campo }\end{array}$} & Modernização da agricultura \\
\hline
\end{tabular}

Fonte: FARIA, 1992. Elaboração própria.

Exceção a este quadro parece ter sido o Instituto Agronômico de Itabira do Mato Dentro, que teve uma existência de 20 anos, desde o final do Império - como Escola Agrícola do Vale do Piracicaba - à primeira década da República. Inicialmente concebida como instituição de ensino prático, voltada para o desenvolvimento da lavoura, a partir da Lei n. 41, de agosto de 1892, "o objetivo do instituto passou a ser o de formar engenheiros agrônomos e técnicos em práticas agrícolas." (BOTELHO, 2008, p. 15). Outras exceções foram os Campos de Demonstração, instituídos em 1895 e extintos em 1898. Apesar da pequena duração dessas experiências, foram relevantes para a formulação da política que vigorou a partir do Congresso Agrícola de 1903. (VERSIEUX, 2010).

Num segundo momento, o ensino agrícola pensado e executado pelo Estado foi fundamentalmente de dois tipos: o primário-elementar e o prático. O primeiro tipo acontecia principalmente nos aprendizados e patronatos agrícolas - sob a alçada do Ministério da Agricultura e do Estado - e nos institutos, sendo o mais representativo da época o Instituto João Pinheiro, inaugurado em 1909, e que funcionou inicialmente anexado à fazenda-modelo da Gameleira. O ensino agrícola prático possuiu diversas modalidades e funcionou em diversas instituições: o ensino ambulante, as fazendasmodelo, as fazendas particulares subvencionadas pelo Estado e os campos de demonstração. (FARIA, 1992).

Fez parte deste segundo momento do ensino agrícola em Minas Gerais a fundação de fazendas-modelo. Estas instituições foram uma iniciativa de João Pinheiro da Silva, então presidente do Estado e existiram como política pública entre 1906 e 1915. Daniela P. Versieux (2010), tomando-as como objeto de estudo em sua dissertação de mestrado, pode compreendê-las como parte do processo de escolarização (FARIA FILHO, 2007) do trabalho agrícola. Em outras palavras, a autora utilizou-se desses estabelecimentos para 
elucidar, em parte, como a aprendizagem do trabalho agrícola, feita tradicionalmente entre as gerações, de pai para filho, passou a ser objeto de ensino, assumindo uma forma eminentemente escolar. Pode, assim, apreender alguns aspectos do processo de escolarização da fazenda, da propriedade rural, tais como as materialidades, os métodos de ensino, os sujeitos do processo de ensino-aprendizagem, o tempo e espaço e a produção de novos conhecimentos escolares.

João Pinheiro, em seu segundo mandato como Presidente do Estado (1906-1908) reduziu o problema econômico mineiro a três termos: "saber produzir, poder produzir e colocar a produção" (jornal Minas Gerais, 9/6/1907, p. 1, col.1) ${ }^{6}$. Ao ensino técnico agrícola caberia exatamente o primeiro destes termos - saber produzir - e para atingir tal objetivo estabeleceu uma seção técnica de agricultura, já prevista nas teses do Congresso Agrícola de 1903, com laboratório de análises químicas; e os campos de demonstração nas fazendas-modelo e colônias de povoamento. Para ele, era a moderna ciência agrícola que ensinaria

[...] as condições de proveitosa exploração do solo, a seleção de sementes, o conhecimento dos adubos mais convenientes". Ensinaria também "a calcular o poder produtivo da terra", garantindo "as colheitas pela previsão das intempéries, $[\ldots]$ indicando com fundamento seguro a especialização de culturas que mais convenham a cada uma das zonas do Estado (jornal Minas Gerais, 9/7/1907, p.1, col.1).

Também coexistiram no período o ensino agrícola médio e o superior, porém instituídos pela iniciativa privada e, muitas vezes, subvencionados pelo Estado. Os exemplos mais significativos foram a Escola Agrícola de Lavras e as Escolas Dom Bosco (Cachoeira do Campo, município de Ouro Preto), ambas de nível médio, e a Escola Mineira de Agronomia e Veterinária, de grau superior, que funcionou em Belo Horizonte. A ausência do Estado na oferta desses níveis de ensino agrícola, aliada à baixa demanda da sociedade, são as razões encontradas por Faria para justificar aí o predomínio das escolas particulares.

A terceira fase do ensino agrícola na Primeira República foi identificada com o fim das fazendas modelo e das subvenções aos fazendeiros (fazendas subvencionadas, campos de demonstração) e a criação, pelo Estado, da ESAV - Escola Superior de Agricultura e Veterinária, instituída por lei em 1920 e inaugurada em 1926 no município de Viçosa: "nesse novo momento, mais que instrumento de organização do trabalho no campo, o ensino agrícola foi percebido como meio de modernização da agropecuária." (FARIA, 1992, p. 310). A partir de então, ainda de acordo com Faria, o Estado passou a investir mais nos níveis secundário e superior, sem abrir mão do ensino agrícola primário.

\section{Ensino agrícola, tradição e modernidade}

O estudo do ensino agrícola na primeira República em Minas Gerais, ligado ao desenvolvimento do Estado, levou-nos a explicitar a relação que se estabelecia à época entre tradição e modernidade na agricultura, pelo viés da modernização. Os chamados métodos tradicionais ou rotineiros da lida com a terra estavam vinculados aos daqueles dos tempos coloniais. Estes, por sua vez, foram baseados na derrubada das florestas, na queimada, no plantio e nas colheitas manuais, trabalho este assentado, sobretudo, na mão de obra dos africanos escravizados. (FERRARO, 2005). Sérgio Buarque de Holanda, lamentando o longo período em que o Brasil ficou aferrado às concepções rotineiras, identificou as origens deste tipo de relação com a natureza no sincretismo entre técnicas 
portuguesas e indígenas. Os portugueses teriam aprendido com os índios suas técnicas rudimentares, sendo que a "técnica europeia serviu apenas para fazer ainda mais devastadores os métodos rudimentares de que se valia o indígena em suas plantações." (HOLANDA, 1995, p. 49). Assim, o autor considera que se deveria

[...] ter em conta que o meio tropical oferece muitas vezes poderosos e inesperados obstáculos à implantação de tais melhoramentos. Se a técnica agrícola adotada aqui pelos portugueses representou em alguns casos, comparadas às da Europa, um retrocesso, em muitos pontos verdadeiramente milenar, é certo que para isso contribuíram as resistências da natureza, de uma natureza distinta da europeia, não menos que a passividade e a inércia dos colonos. O escasso emprego do arado, por exemplo, em nossa lavoura de feição tradicional, tem sua explicação, em grande parte, nas dificuldades que ofereciam frequentemente ao seu manejo os resíduos da pujante vegetação florestal. É compreensível assim que não se tivesse generalizado esse emprego, muito embora fosse tentado em épocas bem anteriores àquelas que costumam ser mencionadas em geral para sua introdução. (HOLANDA, 1995, p. 50).

Holanda (1995) busca algumas causas - a pujante vegetação tropical e a inércia e passividade do colono português - para compreender o atraso brasileiro na agricultura. Vai ainda acrescentar a estas o caráter predatório desse mesmo colono, que via na terra não a propriedade, mas sim um bem que poderia ser usado, explorado, destruído e abandonado logo em seguida.

Assim, a modernização da agricultura estava associada, pelo menos desde o final do século XIX e início do século XX, com a mecanização das lavouras - a substituição parcial do ser humano por máquinas agrícolas - principalmente o arado, e com as técnicas de adubação e irrigação do solo. As máquinas que se queria introduzir na agricultura, nesse período, eram de tração animal e mesmo de tração humana. Além do já citado arado, eram capinadeiras, estrumeiras, semeadores, pulverizadores, cultivadores, destorroadores, destocadores, dentre outras, consideradas símbolos da agricultura moderna, em oposição à agricultura tradicional, herdada dos tempos coloniais. O discurso de Raul Soares ${ }^{7}$, nesse sentido, é esclarecedor. Em 1915, enquanto secretário da Agricultura de Minas Gerais, Soares considerou o predomínio da agricultura tradicional no Estado exatamente pela larga utilização do trabalho manual e "passividade diante das vicissitudes da natureza", idealizando a modernização agrícola como uma

[...] fase de industrialização da Agricultura, em que o homem domina inteiramente a produção, a máquina reduz o braço ao mínimo, a irrigação substitui a chuva, os adubos recompõem os elementos da terra, e os métodos científicos de transformação e conservação dos produtos permitem a procura dos melhores mercados. (MINAS GERAIS, 1915, p. $33)$.

Entretanto, não pudemos aceitar a priori que a rotina devesse necessariamente ser substituída pelos métodos modernos de agricultura. Em fins do século XIX e início do século XX, as elites mineiras, e penso que de outras partes do país, clamavam pela modernização da agricultura. Só para citar um exemplo, Bernardino Lima ${ }^{8}$, deputado mineiro na $1^{\text {a }}$ legislatura, entendia que "a lavoura ressente-se da falta de braços, da falta de processos aperfeiçoados de trabalho, da falta de maquinismo, adotados aos seus diferentes ramos" (CONGRESSO LEGISLATIVO, 1894, p. 101). Vários deputados mineiros citaram 
também, em épocas diferentes, uma iniciativa do governo provincial, de 1831, em introduzir máquinas na agricultura mineira, explicitando que essa preocupação era bem mais antiga, datando do início do século XIX. Relataram que tal iniciativa não havia extrapolado o nível das intenções.

Por outro lado, parte da historiografia vem repetindo esta visão construída pelas elites, da necessidade de mecanização das lavouras. Alguns autores aceitam que a enxada deveria ser substituída pelas máquinas agrícolas, necessariamente, que este deveria ser o caminho natural do desenvolvimento da agricultura brasileira. Sérgio Buarque de Holanda, por exemplo, além de lamentar o prolongado estado rotineiro da agricultura brasileira, como expusemos anteriormente, defendeu com vigor a adoção dos métodos ditos modernos, que eram já de largo e antigo uso na Europa, como o arado. Com efeito, afirmou que "na economia agrária, pode dizer-se que os métodos maus, isto é, rudimentares, danosos e orientados apenas para o imoderado e imediato proveito de quem os aplica, tendem constantemente a expulsar os bons métodos." (HOLANDA, 1995, p. 51).

"Métodos maus"... Essa expressão chamou-nos a atenção. Holanda considerava uns métodos melhores do que outros. Apoiando-se nas pesquisas de um alemão, Dr. Herbert Wilhelmy, datadas de 1939, Holanda enfatizou que as queimadas

[...] além de prejudicar a fertilidade do solo, [...], destruindo facilmente grandes áreas de vegetação natural, trariam outras desvantagens, como a de retirar aos pássaros a possibilidade de construírem seus ninhos. E o desaparecimento dos pássaros acarreta o desaparecimento de um importante fator de extermínio de pragas de toda espécie. O fato é que, nas diversas regiões onde houve grande destruição de florestas, a broca invade as plantações de mate e penetra até a medula nos troncos e galhos, condenando arbustos a morte certa. As próprias lagartas multiplicam-se consideravelmente com a diminuição das matas. (HOLANDA, 1995, p. $68)$.

Correto. Hoje está muito claro para a comunidade científica, para a opinião pública, para diversos setores da sociedade, que as queimadas, o desmatamento, a destruição de habitats trazem sérios danos ao ambiente, e consequentemente à qualidade de vida das diversas populações, inclusive humanas. Encontrei, para Minas Gerais, vários documentos em que a queimada aparece como a grande vilã do esgotamento dos solos, sem a profundidade de análise do Dr. Herbert Wilhelmy, citado por Buarque de Holanda, é forçoso reconhecer.

Porém, os esforços das elites mineiras em suprimir os métodos rotineiros não estavam vinculados à preservação de habitats e à qualidade de vida das populações humanas. Eram necessidades econômicas que as moviam nessa direção. As queimadas provocavam o esgotamento dos solos, a mudança no regime de chuvas e, consequentemente, a diminuição da produção agrícola e dos lucros advindos desta. Por outro lado, o predomínio da enxada, e, portanto, do trabalhador que a manejava, tornavam os produtores dependentes da sazonalidade do trabalhador nacional, particularmente em Minas Gerais onde, como já explicitado, as elites não conseguiram forjar uma imigração europeia massiva, além de perderem trabalhadores para áreas de economia mais dinâmica. Substituir, na lavoura, os homens por máquinas agrícolas era uma necessidade do capital que se formava em fins do século XIX.

Por isso, urgia "arrancar os instrumentos da escravidão - a foice e a enxada - das mãos do lavrador e libertá-lo da miséria pelo manejo do arado e irrigação das plantações. A lavoura precisa ser chamada ao terreno da razão, para daí paulatinamente 
prosperar" (Jornal Minas Gerais, 6/5/1909, p. 4, col. 1, grifos nossos). Aqui, fica mais claro o sentido da modernização da agricultura: a desqualificação dos instrumentos de trabalho tradicionalmente usados pelos pequenos produtores, pelos trabalhadores errantes, pelo meeiro, pelo assalariado. A metáfora de "arrancar" a enxada e a foice das mãos dos lavradores sugere um processo mais violento, mesmo que não tenha se caracterizado como uma expropriação em sentido restrito, da propriedade da terra. Estes trabalhadores podiam, na agricultura tradicional, ter a posse dos seus instrumentos de trabalho $\mathrm{e}$, consequentemente, ter uma existência mais autônoma. Diversamente, na pretendida agricultura moderna, na qual as máquinas agrícolas realizariam boa parte do trabalho, estas eram acessíveis apenas para aqueles que detinham algum capital. Assim, se para Sérgio Buarque de Holanda, os métodos rotineiros eram "danosos e orientados para o imoderado e imediato proveito de quem os aplica", como citado na página anterior, não seria diferente com os "bons métodos" defendidos pelo mesmo historiador.

Por outro lado, Luciano Mendes de Faria Filho percebe o ensino agrícola no governo de João Pinheiro "pensado como elemento central na modernização dos métodos agrícolas e na renovação da mentalidade dos agricultores." (FARIA FILHO, 2001, p. 36). Chamou-nos a atenção essa ideia de "renovar mentalidades". Peter Burke definiu a história das mentalidades como uma abordagem essencialmente durkheimiana das idéias,

[...] embora o próprio Durkheime preferisse a expressão 'representações coletivas'. [...] Os sociólogos e antropólogos contemporâneos falam, às vezes, de 'modos de pensamento', 'sistema de crenças' ou 'mapas cognitivos'. De qualquer forma, o enfoque nas mentalidades atribui "mais destaque a atitudes coletivas do que a individuais; a pressupostos implícitos do que a teorias explícitas, ao 'senso comum' ou ao que parece ser senso comum em uma cultura específica; e à estrutura dos sistemas de crenças, incluindo uma preocupação com as categorias usadas para interpretar a experiência e os métodos de prova e persuasão. (BURKE, 2002, p. 129).

A manutenção da rotina entre os fazendeiros e trabalhadores mineiros era creditada à ignorância do agricultor. Os republicanos mineiros queriam, de fato, mudar costumes, hábitos, enfim, mudar a cultura do agricultor, do lavrador, do criador no que se refere à lida com a terra e com a criação. Pois, de outra forma, o trabalhador nacional não poderia ser empregado em larga escala. E, para isso, realmente seria necessário mudar a estrutura do sistema de crenças desses indivíduos, apesar de que, talvez, não se tenha tido esse entendimento à época.

Rosana Soares de Lima Temperini, estudando as concepções de parcela da elite paulista, entre 1930 e 1937, expressas na revista O Campo, entende que os cientistas vinculados a tal revista, "ao enfatizar a importância do conhecimento racional e da utilização de técnicas na produção agrária, [...] buscavam atuar sobre os indivíduos e suas gerações, modificando hábitos e imprimindo uma nova forma de trabalho." (TEMPERINI, 2003, p. 55). Partindo do conceito de civilização de Nobert Elias, e relacionando-o à modernização, a autora,

[...] pensando no discurso simbólico dos articulistas da revista O Campo afirma que seu pensamento acerca da modernização está precisamente ligado às suas próprias visões sobre civilização/modernização e à percepção dos sertões como a parte não civilizada do nacional. Neste sentido, a cultura do homem do campo, para eles, não possuía uma funcionalidade, ao contrário, ela impedia que o agricultor participasse do 
processo modernizador do mundo agrário.

Nesta conjuntura, o primeiro aspecto da superação da mentalidade tradicional baseava-se na concepção de que era necessário o rompimento do caboclo com o modo de vida amparado no costume de trabalhar apenas na exata medida de suas necessidades mais imediatas. Complementarmente, a defesa da modernização agrícola amparava o princípio de que o mesmo caboclo não repetisse o que lhe ensinara a rotina e passasse a planejar suas atividades a longo prazo. (TEMPERINI, 2003, p. 55).

É preciso ainda explicitar a relação entre modernização e posse da propriedade da terra. O latifúndio constituiu-se em uma herança do sistema de sesmarias adotado pela coroa portuguesa quando da colonização do território brasileiro. Após a independência, a falta de uma legislação sobre terras e a manutenção do trabalho escravo estimulou ainda mais a concentração fundiária. A Lei de Terras de 1850 proibiu as posses, passando a ser a compra o único instrumento de aquisição de terras no país. Como esta lei legitimou tanto as posses ocorridas desde 1822 quanto as sesmarias, a estrutura fundiária não foi alterada (KIRDEIKAS, 2003). Para o autor, "a formação do mercado de terras no Brasil ocorreu sem um grande processo de expropriação, apesar da expulsão de pequenos posseiros ter sido comum no século XIX" (KIRDEIKAS, 2003, p. 28). Em outras palavras, "o homem livre pobre não foi expropriado no sentido próprio do termo (não chegou a ser expulso de sua propriedade), porém teve o seu acesso a terra negado desde os tempos das sesmarias e consumado com a lei de terras de 1850." (KIRDEIKAS, 2003, p. 61).

Após a abolição da escravidão, esse quadro se manteve. Para Lúcio Kowarick,

[...] no processo de transição para o trabalho livre, existe uma condição prévia e fundamental que se refere ao acesso a terra. Enquanto a produção fosse efetuada por escravos, a terra era praticamente destituída de valor, pois sua propriedade só teria significado econômico se seu detentor também possuísse um estoque de cativos. Contudo, a partir do momento que a escravidão começou a apresentar os primeiros sintomas de crise, com o término do tráfico africano, tornou-se necessário impedir que os homens livres tivessem acesso à propriedade da terra. (KOWARICK, 1994, p. 75).

A República inaugurou-se renovando a tradição herdada do Império, mantendo a negação da posse da propriedade aos homens pobres, livres ou libertos. O processo de modernização, pois, deu-se assentado no latifúndio. Alargando o sentido do termo expropriação, Kowarick sugere que

[...] a formação de um mercado de mão de obra livre foi um longo e tortuoso percurso histórico, marcado, na maioria das vezes, por intensa coerção e violência. Para tanto foi necessário efetuar maciça expropriação, que residiu em destruir as formas autônomas de subsistência, impedindo $o$ acesso à propriedade da terra e aos instrumentos produtivos, a fim de retirar do trabalhador o controle sobre o processo produtivo. Mas, além disso, foi também necessário proceder a um conjunto de transformações de cunho mais marcadamente cultural, para que os indivíduos despossuídos dos meios materiais de vida não só precisassem como também estivessem dispostos a trabalhar para outros. (KOWARICK, 1994, p. 12, grifos nossos). 
É necessário reter dessa chave de leitura proposta por Lúcio Kowarick que o processo de expropriação não se restringiu à negação da posse da propriedade da terra, mas estendeu-se às diversas atividades que garantiam a existência de formas autônomas de subsistência da população. Consideramos que o processo de escolarização do trabalho agrícola através do ensino agrícola nas diversas instituições fundadas e/ou mantidas pelo poder público estadual pode ter se ligado a algumas daquelas transformações de cunho mais marcadamente cultural citadas pelo autor. Uma determinada forma de aprendizagem não poderia mais (ou não era mais desejável) que se desse de pai pra filho, no ambiente de trabalho, pois se queria negar ou superar as formas de trabalho predominantes no campo. A enxada e a foice significaram, para as elites, o atraso cultural, a possibilidade do ócio, o trabalho incerto e a recusa do trabalhador em ingressar regularmente no mercado de trabalho. Para o trabalhador do campo, por seu turno, esses instrumentos poderiam ter significado a liberdade, a autonomia, a possibilidade de ter a sua propriedade, a propriedade da terra, ao ocupar terras ainda devolutas. Não é por acaso que até hoje, pelos campos do Brasil, esses instrumentos são símbolos da luta contra a grande propriedade, pela reforma agrária, pela autonomia do homem do campo.

\section{Considerações finais}

Compreendemos que a escolarização da fazenda, a empresa que precisava ser disciplinada, reforçou a concentração e a negação da terra aos trabalhadores. Sem alterar a estrutura fundiária que chegou à República como herança colonial, o governo estadual, apesar de, em alguns momentos, ter seu discurso favorável ao parcelamento das grandes propriedades, como pudemos ler nos documentos deixados por João Pinheiro ${ }^{9}$, não fez mais do que reforçar a lógica dominante. Ao escolarizar o ambiente da fazenda, tentando torná-lo produtivo, o Estado mineiro contribuiu para legitimar o latifúndio improdutivo e o caráter excludente do processo de modernização pelo qual passava a sociedade mineira do início do século XX.

A escolarização da fazenda ligou-se intimamente à escolarização dos instrumentos agrícolas. Houve uma necessidade das classes conservadoras mineiras em introduzir máquinas nos trabalhos da lavoura, seja para diminuir a dependência dos grandes proprietários em relação à mão de obra nacional, seja para aumentar a produtividade das lavouras. Para que a substituição do trabalho vivo por trabalho morto pudesse ocorrer, era preciso desqualificar os instrumentos de trabalho tradicionais, simbolizados pela enxada. Assim, entendemos que a escolarização das máquinas, que já não mais poderiam pertencer ao trabalhador, mas sim ao fazendeiro, correspondeu à expropriação dos instrumentos tradicionais de trabalho, contribuindo em alguma medida para a necessária destruição de formas de vida autônomas dos trabalhadores do campo, do ponto de vista do capital que se formava.

A institucionalização de um tempo de aprendizagem contribuiu também para a disciplinarização do trabalhador agrícola. Ao trazer para dentro da escola o trabalhador, este não podia mais dispor livremente do seu tempo. Controlar o tempo da "vagabundagem", na representação das elites, ou o tempo do ócio e do lazer, assim compreendido por Lúcio Kowarick, foi uma meta perseguida pelas elites durante todo o período abarcado pelo estudo. Não foi possível, contudo, qualificar a contribuição da escolarização do tempo de aprendizagem para a transformação do tempo do ócio em tempo de produção.

A negação e desqualificação dos conhecimentos populares se deram pari passu à escolarização de novos conhecimentos produzidos pela ciência. Métodos e técnicas 
tradicionais, ou rotineiros, faziam parte do repertório de saberes populares e estavam também relacionados às formas autônomas de sobrevivência dos trabalhadores do campo. A qualificação de alguns trabalhadores por meio da escolarização do trabalho agrícola, da prática de um trabalho que não lhes pertencia, que lhes foi imposto, negou-lhes tanto a sua experiência quanto a teoria que informava as práticas novas que se queria introduzir (VERSIEUX, 2010). Essa (des)qualificação, aliada à substituição de homens por máquinas, significou a expropriação do trabalhador de si mesmo, de sua cultura, de suas tradições, de seu sistema de crenças e valores. E contraditoriamente, daquela modernidade que as elites queriam construir. $\mathrm{O}$ duro combate à rotina, em favor da ciência e do progresso material, inseriu-se, pois, nesse quadro mais amplo de formação de um mercado de trabalho livre em Minas Gerais.

\section{Referências}

BARBOSA, Francisco de Assis. As Idéias Políticas de João Pinheiro: cronologia, introdução, notas bibliográficas e textos selecionados. Brasília: Senado Federal/MEC; Rio de Janeiro: Fundação Rui Barbosa, 1980. (Coleção Ação e Pensamento da República).

BAUDRILLARD, Jean. Modernité. In: ENCICLOPÆDIA Universalis. Vol. 11. p.139-141, 1977.

BERMAN, Marshall. Tudo que é sólido desmancha no ar: a aventura da modernidade. São Paulo: Companhia das Letras, 1986. 358p.

BOTELHO, Jorge Florentino. 2008. As políticas públicas para a formação do trabalhador do campo em Minas Gerais: O Instituto Agronômico de Itabira (18801898). Belo Horizonte: Departamento de Pesquisa e Pós-graduação, Centro Federal de Educação Tecnológica de Minas Gerais, 2008. 26f. Projeto de pesquisa.

BURKE, Peter. 2002. História e Teoria Social. Tradução Klauss Brandini Gerhardt, Roneide Venâncio Majer. São Paulo: Editora UNESP, 2002. 275p.

CONGRESSO LEGISLATIVO DE MINAS GERAIS. Anais da Câmara dos Deputados. Belo Horizonte: Imprensa Oficial, 1894.

DULCI, Otávio. João Pinheiro e as origens do desenvolvimento mineiro. In: GOMES, Ângela de Castro (org.). Minas e os fundamentos do Brasil moderno. Belo Horizonte: Editora UFMG, 2005. p. 109-136.

FARIA FILHO, Luciano Mendes de. Escolarização e cultura escolar no Brasil: reflexões em torno de alguns pressupostos e desafios. In: BENCOSTTA, Marcus Levy Alvino (org.). Culturas escolares, saberes e práticas educativas: itinerários históricos. São Paulo: Cortez, 2007. p. 193-211.

República, Trabalho e Educação: a experiência do Instituto João Pinheiro (1909-1934). Bragança Paulista: Editora da Universidade São Francisco, 2001. 174p.

FARIA, Maria Auxiliadora. A Política da Gleba: As Classes Conservadoras Mineiras; discurso e prática na Primeira República. 1992. 394 f. (Tese de Doutorado, História Social). Faculdade de Filosofia, Letras e Ciências Humanas, Universidade de São Paulo, São Paulo, 1992.

FERRARO, Mário Roberto. A gênese da agricultura e da silvicultura moderna no Estado de São Paulo. 2005. 106f. (Dissertação de Mestrado, Recursos Florestais, Conservação de Ecossistemas Florestais). Escola Superior de Agricultura Luiz de Queiroz, Universidade de São Paulo, Piracicaba, 2005.

FUNDAÇÃO JP (revista). O Congresso Agrícola, Comercial e Industrial de Minas Gerais, 
em 1903. Belo Horizonte: Fundação João Pinheiro, v. 11, $n^{\circ s}$. 5/6, mai./jun. 1981. 220p. FURTADO, Celso. Formação Econômica do Brasil. 27 edição. São Paulo: Companhia Editora Nacional: Publifolha, 2000. (Coleção Grandes nomes do pensamento brasileiro). 276p.

HOLANDA, Sérgio Buarque de. Raízes do Brasil. 26 ed. São Paulo: Companhia das Letras, 1995. 220p.

IGLÉSIAS, Francisco. Política Econômica do Estado de Minas Gerais. In: V Seminário de Estudos Mineiros: a República Velha em Minas. Realizado em Belo Horizonte, de 22 a 24 de agosto de 1977. Belo Horizonte: UFMG/PROED, 1982. p. 115-144.

KIRDEIKAS, João Carlos Vieira. O Estado e a formação do mercado interno para o capital no Brasil: 1850-1903. (Dissertação de mestrado, Economia). Centro de Desenvolvimento e Planejamento Regional, Faculdade de Ciências Econômicas, Universidade Federal de Minas Gerais, Belo Horizonte, 2003. 114 fls.

KOWARICK, Lúcio. Trabalho e vadiagem: a origem do trabalho livre no Brasil. $2^{\mathrm{a}}$ ed. Rio de Janeiro: Paz e Terra, 1994. 124p.

LENHARO, Alcir. As tropas da moderação (o abastecimento da Corte na formação política do Brasil - 1808-1842). 2a ed. Rio de Janeiro: Secretaria Municipal de Cultura, Turismo e Esportes, Departamento Geral de Documentação e Informação Cultural, Divisão de Editoração, 1993. 136p.

LIBBY, Douglas Cole. Transformação e trabalho em uma economia escravista: Minas Gerais no século XIX. São Paulo: Editora Brasiliense, 1988. 404p.

MENDONÇA, Sonia Regina de. Agronomia e Poder no Brasil. Rio de Janeiro: Vício de Leitura, 1998. 204p.

MINAS GERAIS (jornal). Belo Horizonte: Imprensa Oficial do Estado de Minas Gerais. 01/set/1906-31/mar/1915.

MINAS GERAIS. SECRETARIA DA AGRICULTURA. Relatório apresentado ao Exmo. Sr. Delfim Moreira da Costa Ribeiro, Presidente do Estado de Minas, pelo Dr. Raul Soares de Moura, Secretário da Agricultura, Indústria, Terras, Viação e Obras Públicas no ano de 1915 [e referente a 1914]. Belo Horizonte: Imprensa Oficial do Estado de Minas Gerais.

MONTEIRO, Norma Góes (coord.). Dicionário Biográfico de Minas Gerais - período republicano - 1889/1991. Belo Horizonte: Assembléia Legislativa do Estado de Minas Gerais, 1994. 2 v.

PIRES, Anderson. Café, finanças e bancos: Uma Análise do Sistema Financeiro da Zona da Mata de Minas Gerais: 1889/1930. 2004. (Tese de Doutorado, História). Faculdade de Filosofia, Letras e Ciências Humanas, Universidade de São Paulo, 2004. 412 fls.

TEMPERINI, Rosana Soares de Lima. O sertão vai virar campo: análise de um periódico agrícola (1930-1937). 2003. 107 f. (Dissertação de Mestrado, História das Ciências da Saúde). Casa de Oswaldo Cruz, FIOCRUZ, Rio de Janeiro, 2003.

VERSIEUX, Daniela Pereira. Modernização e escolarização do trabalho agrícola: as fazendas-modelo em Minas Gerais (1906-1915). 2010. 232f. (Dissertação de mestrado, Educação Tecnológica). Centro Federal de Educação Tecnológica de Minas Gerais: Belo Horizonte, 2010.

WIRTH, John D. O fiel da balança: Minas Gerais na Federação Brasileira (1889-1930). Tradução de Maria Carmelita Pádua Dias. Rio de Janeiro: Paz e Terra, 1982. (Coleção Estudos Brasileiros, v. 50). 384p. 


\section{Notas:}

1 Este texto teve como base a dissertação defendida por Daniela Pereira Versieux (danielaversieux@yahoo.com.br) intitulada MODERNIZAÇÃO E ESCOLARIZAÇÃO DO TRABALHO AGRÍCOLA: AS FAZENDAS-MODELO EM MINAS GERAIS (1906-1915). Contou com o auxílio financeiro da Fundação de Ensino de Contagem, que concedeu uma licença para fins qualificação profissional à sua autora. A pesquisa que originou a citada dissertação fez parte de um programa de pesquisa mais amplo denominado A ESCOLARIZAÇÃO DO TRABALHADOR MINEIRO, coordenado pelo professor Dr. Irlen Antônio Gonçalves (irlen@terra.com.br), cujos subprojetos, A ESCOLARIZAÇÃO DAS ATIVIDADES MANUAIS E A FORMAÇÃO DO TRABALHADOR MINEIRO SOB O PONTO DE VISTA DO LÉXICO REPUBLICANO (1892-1920) e ESCOLARIZAÇÃO E FORMAÇÃO DO TRABALHADOR DO CAMPO EM MINAS GERAIS: análise das reformas educacionais sob o ponto de vista dos discursos do executivo e do legislativo (1892-1920), contam com o apoio financeiro do CNPq e da FAPEMIG, respectivamente.

${ }^{2}$ CONGRESSO LEGISLATIVO DE MINAS GERAIS. Anais da Câmara dos Deputados. Belo Horizonte: Imprensa Oficial, 1894, p. 347.

${ }^{3}$ Maria Auxiliadora Faria (1992) considera a expressão "classes conservadoras" como uma categoria historicamente constituída e não necessariamente uma classe socialmente definida, oposta a outra classe fundamental. Em sua tese de doutoramento, justifica o uso deste termo pela frequência com que aparece nos documentos referentes à Primeira República em Minas Gerais, na qual as classes conservadoras não encerravam "apenas os interesses da agro-exportação [...] significava, [...], o conjunto dos agricultores, comerciantes, dos industriais, dos banqueiros e de todos aqueles que, de uma forma ou de outra, se ligavam ao mundo da produção." (FARIA, 1992, p. 35).

${ }^{4}$ Político e bacharel, Francisco Antônio de Foi deputado estadual (1891-1895), secretário de Estado das Finanças (1894-1898), eleito senador estadual (não chegou a tomar posse), prefeito de Belo Horizonte (1899), deputado federal (1900-1902) e presidente do Estado (1902-1906). Atuou ainda como senador da República (1906-1910; 1915-1923) e ministro das Finanças (1910-1914).

5 Político, industrial e bacharel, João Pinheiro foi um dos fundadores do partido republicano em Minas Gerais, ocupando cargos de relevo no primeiro governo da República, além de assumir interinamente o cargo de presidente do Estado, em 1891. Foi eleito deputado no Congresso Constituinte do Estado e renunciou ao mandato em 1891 e retirou-se em Caeté, onde fundou uma fábrica de cerâmicas, dedicando-se também à docência na Faculdade Livre de Direito (MONTEIRO, 1994). Voltou à vida pública em 1899 eleito vereador do município, onde passou a exercer a função de Agente Executivo e Presidente da Câmara Municipal. Em 1903, presidiu a Comissão Fundamental do Congresso Agrícola, Industrial e Comercial. Logo em seguida foi eleito senador da República (1905) e Presidente de Minas Gerais (1906-1908).

${ }^{6}$ A autoria deste e de alguns outros artigos, publicados na forma de editoriais, é atribuída a João Pinheiro da Silva (VERSIEUX, 2010; BARBOSA, 1980).

${ }^{7}$ Político, jurista, professor e escritor, Raul Soares de Moura iniciou suas atividades políticas em Rio Branco (atual cidade de Visconde do Rio Branco) em 1910, elegendo-se vereador e chefe do executivo municipal. Foi deputado estadual (1911-1914), secretário da Agricultura, Indústria, Terras, Viação e Obras Públicas (1914-1917), Ministro da Marinha (1919-1922) e Presidente do Estado de Minas (1922-1924), de acordo com MONTEIRO (1994).

${ }^{8}$ Político, advogado e professor, Bernardino Augusto de Lima foi professor na Escola de Minas de Ouro Preto e Deputado ao Congresso Constituinte mineiro e na primeira legislatura (1891-1895), além de senador do Estado (1895-1898). Foi considerado por Monteiro (1994) como pioneiro da campanha de mecanização agrícola do Estado.

${ }_{9}^{9}$ Ver, por exemplo, os editoriais publicados pelo Jornal Minas Gerais entre novembro de 1906 e junho de 1907 cuja autoria é atribuída a João Pinheiro da Silva (VERSIEUX, 2010, anexos). Ver também BARBOSA (1980).

Recebido em: $\quad$ 26/07/11

Aprovado em: $\quad 31 / 01 / 12$ 